\title{
Arvedi ESP Technology - The Hot Rolling of HS and AHS Thin Gauge Steel Strips
}

\author{
Roberto Venturini ${ }^{1, a^{*}}$, Paolo Daniele Avancini ${ }^{1, b}$, Nicola Barbier $^{1, c}$ \\ and Alessandro Rizzi ${ }^{1, d}$ \\ ${ }^{1}$ Acciaieria Arvedi, Via Acquaviva 18, 26100 Cremona \\ aroberto.venturini@ast.arvedi.it, baolodaniele.avancini@ast.arvedi.it, \\ cnicola.barbieri@ast.arvedi.it, ${ }^{d}$ alessandro.rizzi@ast.arvedi.it
}

Keywords: Arvedi ESP, endless, HR thin gauges, multi-phase steel, high quality HSLA steel.

\begin{abstract}
After 5 years from start-up, Arvedi ESP Technology has achieved outstanding performances in terms of production, products and quality. The technology has proved particularly suitable for the production of thin gauge strips $(<2 \mathrm{~mm})$. This paper presents the experiences in the production of high strength and advanced high strength steels, such as micro-alloyed S550MC, dual phase DP600 and ferritic bainitic HR60 in thin gauge strips on the ESP line of Acciaieria Arvedi S.p.A. in Cremona. Some aspects of the industrial production process for these steel grades are highlighted on the basis of casting and rolling parameters and microstructural and mechanical investigation.
\end{abstract}

\section{Introduction}

Many innovations have been introduced in the hot strip mill over the years; these have been due to technological developments in mechanical, electrical and automation knowledge and these innovations represent a key factor to save energy and associated costs. The most radical way and with the highest potential is through the elimination of as many production steps as possible by directly delivering hot rolled products in place of cold rolled ones. Since 1989 new generations of hot strip mills have been realized based on thin slab technology, but Arvedi ESP (Fig.1), operating since 2009, is the first and today the only example of a fully endless production line. The plant allows production of more than two million tons per year of a wide range of steel grades (low carbon, alloy steel, HSLA, DP) with a range of strip thicknesses from 0.8 to $12 \mathrm{~mm}$ [1].

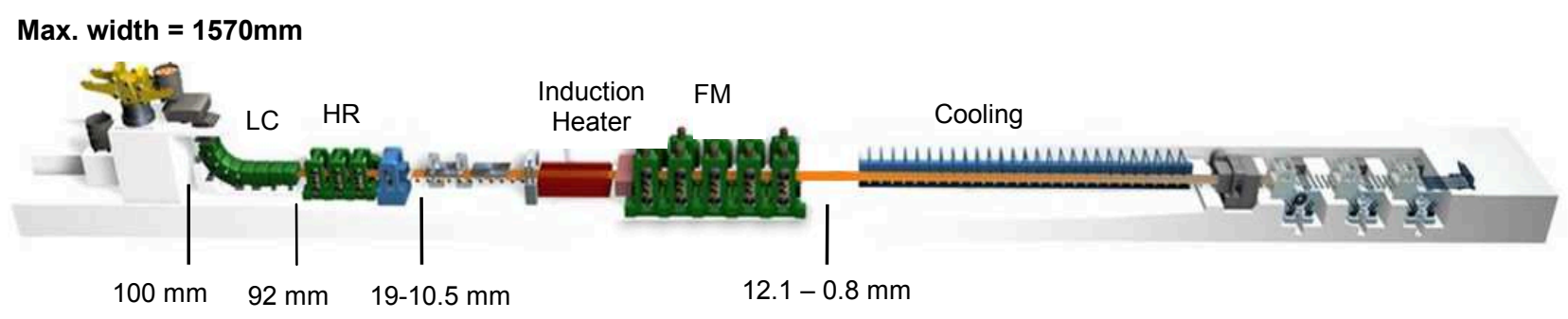

Fig. 1 - Arvedi ESP layout.

The ESP line is composed of several sections: thin-slab caster performing soft reduction and cast rolling, induction heater, finishing mill and cooling line, high speed shear and three downcoilers. The total plant length is about $190 \mathrm{~m}$, this makes the Arvedi ESP line the most compact of TSCR (Thin Slab Casting and Rolling) technologies.

Production of high quality HSLA and multi-phase steels via the TSCR route presents several metallurgical challenges [2] which must be overcome to meet the required properties (mechanical, surface and internal). Recent works $[3,4]$ show the results of metallographic examinations on this slab and strip as well as the numerical simulation of microstructural evolution (precipitation of 
$\mathrm{NbC}$, grain size). The results indicate a very high level of efficiency in the exploitation of the added micro-alloying elements over conventional steel production for HSLA steel grades.

This work is focused on describing some aspects of the industrial production process and the investigation of the metallographic and mechanical properties for thin gauge HSLA and multi-phase steel strips.

\section{The ESP Casting and Rolling Process}

Casting and rolling affect the most important quality characteristics of the final product. The quality demands HS and AHS steels are higher in terms of: steel cleanness, internal soundness, homogeneous mechanical properties, homogeneous microstructure and surface quality [5]. The internal soundness of cast thin slabs is mainly determined by segregations and the existence of hot tear segregations. The centre of the thin slabs is virtually free from porosities, and the enrichment of segregating elements is moderate. This is an important prerequisite for a homogeneous formation of microstructure in the final product but also for the prevention of the formation of large primary nitrides and carbides in the casting of microalloyed steels. In the Arvedi ESP process, the bow-type caster with funnel-shaped mould provides stable operating conditions (low break-out rate). Additional features such as the innovative strand support system and the dynamic control of secondary cooling and liquid core reduction promote the favorable development of the strand centre regarding centre segregation and prevent the formation of hot tear segregations. The endless production mode ensures process controllability and increased homogeneity of the final product properties with stable production windows for all products. In particular, this is a consequence of constant production speeds and temperature profiles through all the process steps from casting and roughing to inductive reheating, finishing rolling and strip cooling. The extraordinarily high process stability along the ESP line lays the basis for the optimization of alloying concepts and enables the selection of processing parameters very close to plant limits. This advantage becomes especially striking if exploited for advanced high strength steel grades, as demands in terms of process stability, alloying costs and rolling loads are at a maximum. Besides its stability, a major advantage of the Arvedi ESP layout is its two-step rolling concept as it allows for precise control of the microstructure in the final product. The main purpose of the high reduction mill (HRM) directly placed behind the caster exit is the complete elimination of the as-cast microstructure. This results in a more homogeneous recrystallised microstructure at the exit of the high reduction mill. Accordingly, rolling schedules take into account the inhomogeneous temperature profile [6] along the thickness direction and are designed to take maximum advantage of the homogenization effect. The direct linking of induction heater $(\mathrm{IH})$ and finishing mill (FM) train in conjunction with a properly chosen cooling strategy permits precise microstructure engineering for micro alloyed steels (Fig. 2).

The start of rolling in the non-recrystallisation regime can be shifted between the $2^{\text {nd }}$ and $5^{\text {th }}$ rolling step by a corresponding adjustment of induction heater power and pass schedule setup. The two-step rolling concept including the induction heater not only leads to a high quality of the final product geometry but also facilitates control of the target microstructure, which is critical for achieving suitable mechanical properties of the finished strip [7]. Simulations point out that in low carbon HSLA steels the fine ferrite grains make up about $54 \%$ of the total yield strength (precipitation strengthening is about $10 \%$ and other mechanisms such as solid solution $36 \%$ ) [4]. 


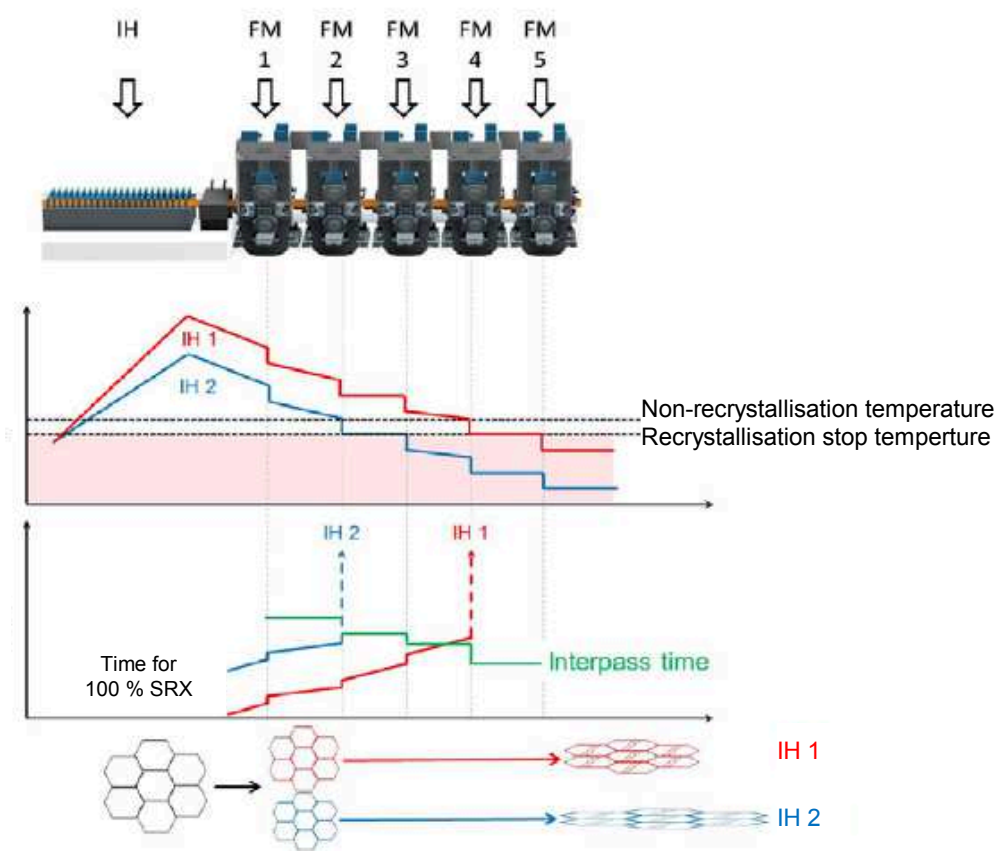

Fig. 2 - Temperature and microstructure evolution in the induction heater and finishing train area of Arvedi ESP plant: by properly choosing the induction heater IH exit temperature and pass schedule, precise microstructure engineering for micro alloyed steels is accomplished [4].

\section{Results and Discussion}

In the last few years an intensive development plan has been carried out by Acciaieria Arvedi on the ESP plant in Cremona with the aim of industrializing the production of thin gauge HSLA steel with high yield strength $(>500 \mathrm{MPa}$ ) and multi-phase steel (ferritic-bainitic HR60 and ferriticmartensitic DP600 microstructure). It is clear from the previous section that the production of these challenging steel grades with endless technology has required careful design of the steel chemistry, rolling and cooling schedule. To reduce the risk of longitudinal cracking occurring during casting in TSDR processes, great attention has to be paid to the chemical composition of the steel. If processing is carried out in the hypoperitectic range ( $0.09 \mathrm{wtp}$ to $0.17 \mathrm{wtp}$ carbon content) the risk is even higher. Therefore a balance between mechanical properties and chemical composition was taken into account during the development of these steel grades. The chemical composition and the main process parameters of the most recent trials are reported in Tab. 1. Roll force values in the table are related to low carbon mild steels with the same thicknesses. The slight difference demonstrates that the ESP process allows these steel grades to be obtained without many risks, without shape defects and without instability that may appear if roll forces were at maximum value.

Tab. 1 - Chemical analysis (\%wt) and main process parameters.

\begin{tabular}{|c|c|c|c|c|c|c|c|c|c|c|c|}
\hline Steel Grade & $\begin{array}{c}\mathrm{V} \\
\text { cast }\end{array}$ & $\begin{array}{c}\text { Slab } \\
\text { th. }\end{array}$ & $\begin{array}{l}\text { Bar } \\
\text { th. }\end{array}$ & $\begin{array}{c}\Sigma \text { Roll } \\
\text { Force } \\
\text { HRM }\end{array}$ & $\begin{array}{c}\Sigma \text { Roll } \\
\text { Force } \\
\text { FM }\end{array}$ & Coil th. & $\mathrm{C}$ & $\mathrm{Mn}$ & $\mathrm{Si}$ & $\mathrm{Nb}$ & V \\
\hline & $\begin{array}{c}{[\mathrm{m} /} \\
\mathrm{min}]\end{array}$ & [mm] & {$[\mathrm{mm}]$} & {$[\mathrm{MN}]$} & {$[\mathrm{MN}]$} & {$[\mathrm{mm}]$} & $\begin{array}{l}{[\%]} \\
\max \end{array}$ & $\begin{array}{l}\%] \\
\max \end{array}$ & $\begin{array}{l}{[\%]} \\
\max \\
\end{array}$ & $\begin{array}{l}{[\%]} \\
\max \end{array}$ & $\begin{array}{l}{[\%]} \\
\max \end{array}$ \\
\hline DP600 & 5.3 & 92 & 11 & $+21 \%$ & $+7 \%$ & 1.5 & 0.08 & 1.20 & 0.30 & - & - \\
\hline HR60 & 5.3 & 92 & 14 & $+18 \%$ & $+5 \%$ & 2 & 0.08 & 1.40 & 0.20 & 0.03 & - \\
\hline S550MC & 5.3 & 92 & 12 & $+15 \%$ & $+5 \%$ & 1.75 & 0.06 & 1.50 & 0.40 & 0.03 & 0.06 \\
\hline
\end{tabular}

Samples for metallographic and mechanical characterisations were taken from different regions (Fig. 3) of the strip for all the steel grades analysed. The tested specimens were prepared by 
mechanical polishing and chemical etching (Nital $2 \%$, LePèra and Picral). The metallographic analysis was performed along the rolling direction. The tensile strength was determined by a Galdabini PMA/50 test machine. The tests were performed in accordance with international standard ISO 6892.

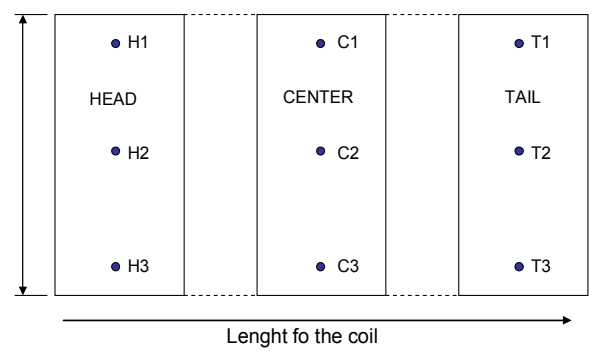

\section{H1,C1,T1: $10 \mathrm{~cm}$ Operator Side \\ H2,C2,T2: middle of the width \\ H3,C3,T3: $10 \mathrm{~cm}$ Drive Side}

Fig. 3 - Map of sampling.

The mechanical tests (Tab. 2) showed a good homogeneity of properties along the length of the strip and along the width. The values on head, centre and tail of the coils remained in a range of about $20 \mathrm{MPa}$.

Tab. 2 - Average mechanical properties of the different steel grades for coil head (H1-H2-H3), centre (C1-C2-C3) and tail (T1-T2-T3), with their standard deviations in brackets.

\begin{tabular}{|c|c|c|c|c|c|c|c|c|c|c|}
\hline \multicolumn{2}{|c|}{ Steel Grade } & \multicolumn{3}{|c|}{ DP600 } & \multicolumn{3}{c|}{ HR60 } & \multicolumn{3}{c|}{ S550MC } \\
\hline \multicolumn{2}{|c|}{ Positions } & Head & Centre & Tail & Head & Centre & Tail & Head & Centre & Tail \\
\hline $\mathrm{Rm}$ & {$\left[\mathrm{N} / \mathrm{mm}^{2}\right]$} & $615(8)$ & $604(7)$ & $609(6)$ & $612(7)$ & $607(5)$ & $608(5)$ & $603(8)$ & $601(5)$ & $600(8)$ \\
\hline $\mathrm{Re}$ & {$\left[\mathrm{N} / \mathrm{mm}^{2}\right]$} & $420(7)$ & $410(6)$ & $405(4)$ & $521(5)$ & $525(6)$ & $527(5)$ & $552(7)$ & $555(9)$ & $551(5)$ \\
\hline $\mathrm{Al}$ & $\%$ & $21(2)$ & $25(2)$ & $23(2)$ & $18(2)$ & $18(2)$ & $18(2)$ & $22(2)$ & $20(1)$ & $21(1)$ \\
\hline
\end{tabular}

The very good performance of Arvedi strips was confirmed by the bend test according to ISO 7438 standard. Fig. 4 shows the results for S550MC grade where no cracks are detectable on the surface after very severe deformation $\left(\mathrm{D} / \mathrm{th} \sim 0.6180^{\circ}\right)$.

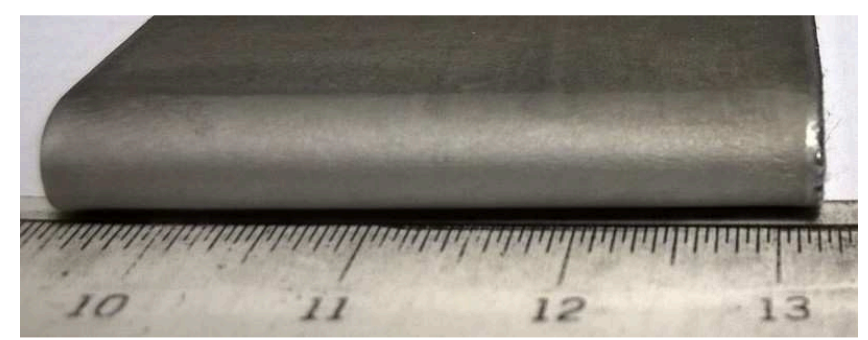

Fig. 4 - Bend test on S550MC Diameter/thickness $\sim 0.6-180^{\circ}$

As a result of the Arvedi ESP process and its efficiency in exploiting microalloying elements, the microstructural analysis (Fig. 5) in all the samples shows a very fine microstructure (for S550MC ASTM E112-10 G = 13). In contrast with the ferritic microstructure of HSLA low carbon steels, multiphase steel consists of either ferrite/martensite mixtures or a ferritic/bainitic structure (dual phase steels). The grain size and the percentage of the second phase are very homogeneous and the difference in the coil (head, centre, tail) is negligible. 


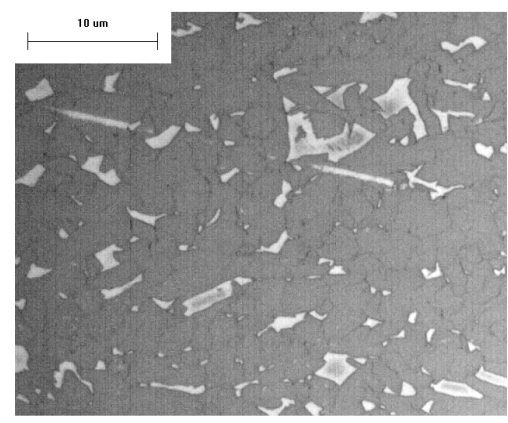

(a)

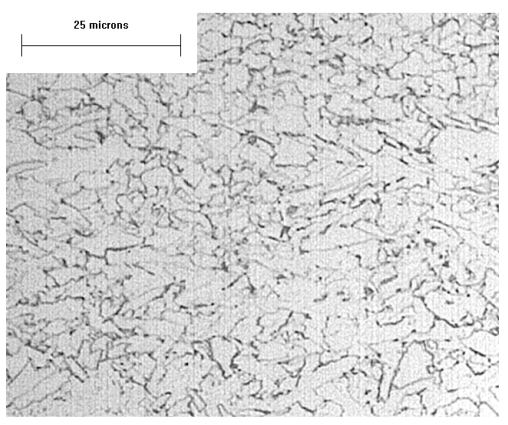

(b)

LePèra, 1000X

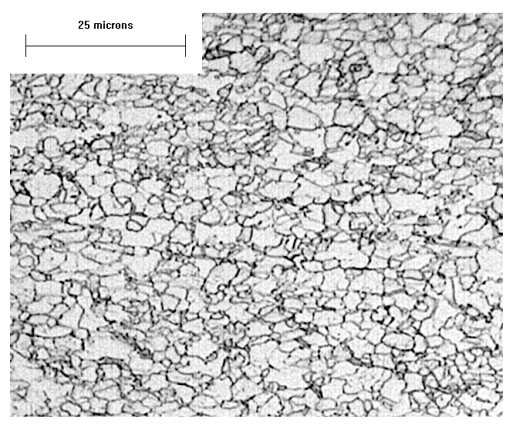

(c)

Nital, 500X

Fig. 5 - Metallographic analysis at 1/3 thickness: (a) DP600, (b) HR60, (c) S550MC.

The investigated steels have a higher manganese and silicon content compared to low carbon steels: for these grades homogeneity is one of the most important requirements. The final applications are mainly automotive safety components and all types of meso- and macrosegregation, such as centre segregations and hot tear segregations, have proved to be harmful. In the Arvedi ESP plant, the bow-type caster with funnel-shaped mould provides stable operating conditions. Additional features, such as the innovative strand support system and the dynamic control of secondary cooling and liquid core reduction, promote the favorable development of the strand centre as regards centre segregation and prevent the formation of hot tear segregations.

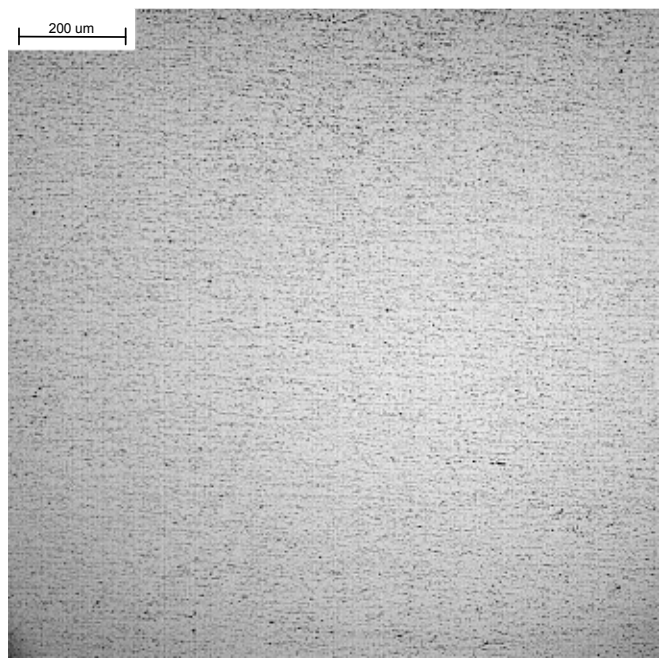

(a)

Picral, 500X

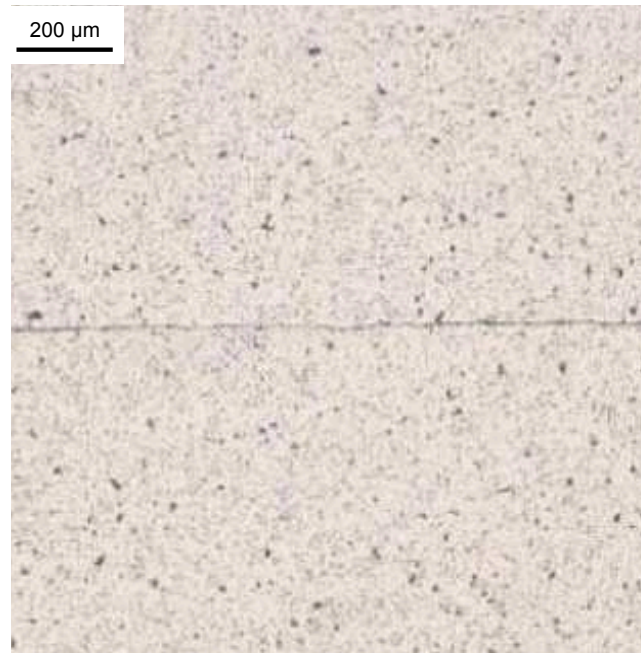

(b)

Reference Image

Fig. 6 - Metallographic analysis on the entire thickness.

Fig. 6 compares a reference image of maximum central segregation that is acceptable for an automotive customer, and a typical microstructure for S550MC steel grade.

\section{Conclusions}

The result of the first industrial trials for DP600, HR60 and S550MC indicate that the Arvedi ESP process is very efficient for rolling thin gauge high quality strips while respecting the quality requirements for the production of HSLA and other steel grades such as complex phase ones (i.e for automotive applications). The endless production route guarantees excellent homogeneity of the final product, as highlighted by the microstructural and mechanical characterizations, and the associated precise adjustment of the material properties. 


\section{References}

[1] G. Arvedi, F. Mazzolari, J. Siegl, G. Holleis, Arvedi ESP (Endless Strip Production) first thin slab endless casting ans rolling results, Ironmaking \& Steelmaking, Volume 37, Issue 4 (01 May 2010), pp. 271-275

[2] J. Rodriguez-Ibabe, Thin Slab Direct Rolling of Microalloyed Steels, Trans Tech Publications, Switzerland, (2007), p. 79

[3] A. Guindani, R. Venturini, C. Mapelli, S. Barella, A. Gruttadauria, D. Mombelli, Properties of hot rolled steel strips produced by endless casting-rolling plant, La Metallurgia Italiana, n. 1 (2014), pp. $25-51$.

[4] S. Bragin, A. Rimnac, B. Linzer, A. Bianchi, A. Mantova, A. Rizzi, C. Bernhard, Arvedi ESP Process - An ultimate technology connecting casting and rolling in endless mode, $9^{\text {th }}$ International Rolling Conference, Venezia, Italia (2013).

[5] M.M Wolf, Elements of solidification control in the continuous casting of billets and blooms, Materials Plant and Technology 30 (1983), 46-59.

[6] M. Schmidtchen, A. Rimnac, B. Linzer, R. Kawalla: Simulation of hot rolling in roughing sections of ESP mills, MEFORM 2013, Freiberg, (2013).

[7] A. Guindani, R. Venturini, A. Rimnac, B. Linzer, C. Bernhard, S. Bragin, Thermomechanical processing of low-carbon steels on Arvedi endless strip production lines: Modelling and plant results, 4th international conference on thermomechanical processing of steels (TMP2012), Sheffield, UK, (2012)

[8] A. Flick, A. Wagner, In Linking of Casting and Rolling - A Key Technology for the Future of Steel, International Symposium on Thin Slab Casting and Rolling, Nanjing, China, Nanjing, China, (2009); pp 73-79. 